\title{
Pedagogical Conditions of Formation of Technical Culture of Market Education Engineers
}

\author{
Tetiana Zhytomyrska [0000-0002-7015-0819], Marina Musorina* [0000-0002-0769-2199]
}

\author{
Danube Institute of the National University «Odessa Maritime Academy», Izmail, Ukraine \\ *mmarinalex17@gmail.com
}

\begin{abstract}
In modern conditions, high demands are placed on applicants for higher education in the maritime industry, their employers: crewing companies, maritime agents, representatives of seaports. It must be a person with a highly developed general, professional and technical culture. In our article some pedagogical conditions of formation of technical culture of applicants of higher education of sea branch are considered. The policy of the state, which is aimed at a breakthrough in politics, economics, industry and production, in science will not succeed without competent professionals, the maritime complex, who have a highly developed technical culture. Without solid knowledge of fundamental disciplines, it is impossible to understand the technique and technological processes, manage them, creatively participate in the development of projects in the field of science-intensive industries, innovative technologies. As the innovative renewal of the technical base of maritime transport is extremely accelerated and the competition between shipping companies for the introduction of the latest advances in technology and technology is growing, it is necessary to improve the pedagogical conditions for the formation of technical culture of maritime cadets. Therefore, the purpose of this study is to identify the latest technologies for teaching technical disciplines in order to train competitive in the global labor market applicants for higher education, which due to the high quality of training will meet the requirements of the world's leading shipping companies. The idea of continuing education finds its application in the reform of education, especially in the current conditions of rapid formation of science and technology, the creation of science-intensive industries, integration into the world, globalization and more.
\end{abstract}

Keywords: technical culture, pedagogical conditions of formation, applicants for higher education in the maritime industry.

\section{INTRODUCTION}

The processes taking place in Ukraine today cover all spheres of our life - cultural, educational, security and health care, production, strengthening international contacts, increasing the exchange of experience in science, technology and other fields. New productions equipped with the most modern equipment appear, modernization of old enterprises is carried out, conditions and opportunities of educational activity are updated. In these conditions, high demands are placed on the modern applicant for higher education, maritime direction, and so on. Educational activity forms not just a competent specialist, but a creative person with a highly developed technical culture, deep knowledge, well-developed intellect, ability to think outside the box, make original decisions, be able to convince of their truth, prove and take responsibility for their actions. In addition, to be not only a highly qualified professional, but also a competitive specialist, a person must be in the process of continuous self-formation, within the modern systematic updating of pedagogical conditions for the formation of technical culture of maritime higher education. Scientific achievements in the field of information technologies at the beginning of the 21 st century led to the development of the concept of personal education (PLE - Personal Learning), the idea of which was to provide educators and curators of e-courses with the ability to customize training to the needs of each individual trainee. The concept of "Personalization of education" is broader than simply "individualization" or "differentiation", since it gives the learner a definite choice of what is being studied, when it is studied and how it is studied [1].

\section{MAIN MATERIAL}

The existing system of maritime education at the Danube Institute of the National University "Odessa Maritime Academy" (DI NU "OMA") complies with the 
Council of Europe Convention and UNESCO "International Convention on Training and Certification of Seafarers on Watch", so graduates of our DI NU "OMA" are not experiencing difficulties in the international labor market, during employment. This is facilitated by the annual increase in the number of higher education applicants and teachers of OMA, who are part of international mobility, international internships and internships on ships of shipping companies in Germany, the Netherlands, Greece, Great Britain, USA, Liberia, Turkey, Cuba, Algeria. other maritime states, and after graduation are fully employed.

Maritime higher educational institutions always play a key role in the formation of culture, including technical, in the transmission of cultural values from one generation to another, in the education of the intelligentsia, in the creation of an educated stratum of society. Maritime education has always been universal and fundamental, we emphasize that today's society has largely lost its position. There are many reasons for this: insufficient state funding for higher professional maritime education, cancellation of state orders for graduates. The reforms carried out in the system of primary, secondary and specialized schools have not improved the quality of students' knowledge, and we would like the best qualities of higher education in Ukraine to be preserved in the current conditions of education reform.

The policy of the state, which is aimed at a breakthrough in politics, economics, industry and production, in science will not succeed without competent professionals, the maritime complex, who have a highly developed technical culture. Without solid knowledge of fundamental disciplines, it is impossible to understand the technique and technological processes, manage them, creatively participate in the development of projects in the field of science-intensive industries, innovative technologies. As the innovative renewal of the technical base of maritime transport is extremely accelerated and the competition between shipping companies for the introduction of the latest advances in technology and technology is growing, it is necessary to improve the pedagogical conditions for the formation of technical culture of maritime cadets.

Therefore, the purpose of this study is to identify the latest technologies for teaching technical disciplines in order to train competitive in the global labor market applicants for higher education, which due to the high quality of training will meet the requirements of the world's leading shipping companies. The idea of continuing education finds its application in the reform of education, especially in the current conditions of rapid formation of science and technology, the creation of science-intensive industries, integration into the world, globalization and more.

Higher professional maritime education must meet the demands and capabilities of society, must prepare professionals for life and productive work in society. Such a specialist must meet certain requirements. Education should develop in future professionals such qualities as dynamism, mobility, adaptability, creative approach to solving problems of varying complexity based on existing knowledge, the need for continuous self-formation and improvement.

According to W. Buchanan, President of the American Society for Engineering Education - ASEE, at the moment, around the world, the problem of staff shortages is acute. Maritime activities involve the fundamental training of future professionals, deep, solid knowledge in disciplines such as mathematics, physics, chemistry, drawing, engineering and computer graphics. In addition, the future specialist must have the following basic principles: social skills, ethics, the ability to exalt themselves, to have a highly developed technical culture.

Thus, during the study of practical aspects of the formation of pedagogical conditions for the formation of technical culture of higher education to professional maritime activities, we faced the need to identify and introduce into the educational process of higher maritime school pedagogical conditions that will increase efficiency in this area. We believe that this will enhance the effectiveness of professional training, ensure the continuity of the educational process in higher education institutions (HEI), update the cadet's awareness of their professional development, provide feedback between the subjects of the educational space of the maritime profile.

The scientific term "pedagogical conditions" means an interconnected set of internal and external parameters that ensure high efficiency of the process of formation of higher education in all components of readiness for teaching. It should be noted that the pedagogical conditions were determined by us, based on the theoretical and practical foundations of the organization of the educational process in HEI. In particular, the pedagogical conditions are singled out in such a way that they have the maximum impact on all components of the readiness of higher education students for professional future activities. Thus, we believe that the following pedagogical conditions provide an effective influence on the formation of the readiness of higher education students for professional activities in the maritime complex:

\subsection{The use of information technology in the process of educational activities}

In today's conditions. An important role in improving the quality of education is played by information technology (IT), they are widely used in the educational process of all educational institutions. The most common means of their use are computers. So, for example, when studying courses "Chemistry", "Safety at sea", "Physics", so here: working programs provide performance of laboratory works by means of the virtual workshop 
representing a set of works on all parts of discipline. The undoubted advantage of a virtual workshop is its clarity. There are a number of experiments that cannot be performed in the laboratory conditions of HEI. The obligatory agreement of application of information technologies in the course of educational activity, is existence of a computer class, the software and specially developed methodical maintenance for performance of virtual laboratory works. It should be noted that computer work should not replace a traditional laboratory workshop, but organically complement it in the learning process $[2-5 ; 6]$.

\subsection{The use of electronic textbooks in the educational process}

In addition to traditional paper media (textbook, guidelines), electronic manuals can be used. This manual, in the first place, can be an electronic textbook, it has a number of advantages over traditional textbooks, but at the same time has its own features, the advantage of an electronic textbook is compactness, large amount of information, a course of lectures adapted to specific freelancers, and his program in a particular discipline, guidelines for laboratory and practical work, programs for test control and self-control of the level of knowledge of cadets, additional training materials. etc. It should be noted that all this information presented in electronic resources can be systematically adjusted: supplemented, updated, etc.

\subsection{Activation of independent work of students}

Given the significant reduction in hours devoted to the study of basic disciplines, the independent work of students becomes especially important, and, most importantly, the implementation of teacher control over the activities of cadets.

It is possible to differentiate several types of independent work of cadets: during laboratory and practical employments, seminars, lectures; extracurricular work of cadets on homework; independent study of any topic, preparation of reports and abstracts, their defense; preparation and holding of consultations, tests and exams. Thus, we can imagine two areas of independent work of cadets: work carried out under the guidance of a teacher, and independent work organized by the cadet at its discretion [7].

\subsection{Systematic control of the level of knowledge and skills of students}

Management of educational activities is a systematic control of the level of knowledge and skills of cadets. He can be called external - a teacher, and internal - is the selfcontrol of cadets. There are the following forms: oral examination, colloquium, written work - independent, control, can be conducted in the form of testing, including the use of computer programs.
Conducting a colloquium in the form of testing by information technology has a number of advantages over traditional:

$>$ objectivity of assessment of the level of knowledge (the bias of the teacher is completely excluded);

$>$ the possibility of testing with a large number of cadets at the same time;

$>$ significant savings in teacher time - online verification of answers and grading.

Input control of the level of knowledge and skills of cadets should become obligatory, especially for basic disciplines of a technical direction, this control allows to estimate a real level of knowledge of cadets of HEI. This is necessary for the timely adjustment of the educational process to pay more attention to the weaknesses of the training of cadets and prepare them for high, compared to the school, the requirements of the Free Economic Zone [8].

\subsection{Conducting scientific seminars of technical orientation, mini-conferences, presentations on syllabus topics}

This condition can be based on the independent work of cadets, performed, for example, in groups of 2-3 people, the group prepares a short report, a presentation on a topic proposed by the teacher, and speaks with him at a mini-conference. This condition seems effective because it has many positive aspects: it instills the skills of collective creativity, systematic work with gadgets, computer, electronic media, develops the ability to present themselves, to find the necessary information in different types of sources.

Cadets gain additional knowledge, competently and interestingly present updated information, gain experience of speaking to the audience, thereby developing competitiveness, speech culture, technical culture, and as a result - their general culture.

\subsection{Strengthening interdisciplinary links}

Technical culture is a set of cultures of other disciplines. To become a highly qualified specialist in the future and current cadet you need to have solid knowledge of basic, fundamental disciplines: physics, mathematics and chemistry, computer science. Together, these subjects, including, of course, the humanities: history, philosophy, culturology, form the cadets' worldview, a holistic scientific picture of the world, thus developing, and technical culture. It should be recalled that universities have long studied disciplines at the intersection of sciences, such as biophysics, biochemistry, physical chemistry or chemical cybernetics, so that without basic knowledge it is impossible to master these disciplines, and strengthening interdisciplinary links is a matter of time. 


\subsection{Involvement of students in research activities}

Another important condition for the formation of technical culture is the involvement of cadets in research work within the technical area. In the conditions of higher maritime professional education, for cadets it is possible to organize excursions to research institutes and centers of shipping, ship repair and shipbuilding plants, to organize for them performances of scientists, to acquaint with cadets and postgraduate students engaged in scientific developments at profile departments, to invite to conferences. held for young scientists.

Scientific conferences, seminars and webinars with the participation of leading scientists of the Danube Commission, the Academy of Pedagogical Sciences of Ukraine, Prat of the Ukrainian Danube Shipping Company regularly take place in DI NU "OMA", which gives young scientists time to solve urgent problems.

\subsection{Information and educational environment in $\mathrm{HEI}$}

The formation of the technical culture of cadets is facilitated by the systematically updated information and educational environment of the Free Economic Zone, which requires a regular increase in the level of information and technical culture and applicants, and equally high requirements for management and teaching staff. Managers should be interested in graduating qualified, in-demand specialists with a highly developed information and technical culture, which ensures, first of all, the prestige of the university, and a diploma of such a university serves as a high guarantee for the graduate's employment.

Of great importance is the IT readiness of the teacher, his ability to arouse the interest of the cadet in his subject with his indifference, creative approach to preparation for the lesson, whether a lecture, laboratory or practical classes. Effective lecturing is manifested in the flexible management of cognitive activity of cadets, stimulating creative initiative, personality formation, it is necessary to increase the motivation of cadets to master the material in advance not only on pre-prepared by the teacher electronic abstracts, but also to use other additional sources to stimulate initiative. An additional measure of motivation to prepare for the lesson and attentive perception of the content of discussions is to conduct an express survey at the end of the pair on the content of the just listened to the lecture - conversation. Equally friendly, equal, friendly relations with cadets also play a big role. Cadets evaluate the teacher not only by the level of his professional knowledge, but, first of all, by the level of his preparedness, ability to communicate friendly, positive behavior, manner of dress, attitude to cadets and colleagues, to educational activities in general. The respect that cadets feel for their teacher is expressed in the attitude to his subject, in a more thorough preparation for classes, a stricter attitude to themselves, which in turn benefits both the teacher and the cadets, stimulating and motivating, thereby, further creative self-improvement and self-development [9]

The main task of the teacher in practical classes in technical disciplines is the ability to analyze information presented in electronic form, etc., to draw conclusions and find effective solutions. The acquisition of such skills will be facilitated by discussion of problems, discussions based on the analysis of specific situations, cases, materials of swimming practice of cadets and students.

\subsection{Activation of skills of performance by applicants of higher education of tasks of a technical direction by means of IT}

Currently, almost all students in HEI use IT, which simplifies the process of finding information, processing it and presenting it in various presentation forms. The use of gadgets and computers as tools of creative activity in the technical direction, contributes to the following goals:

- increase motivation for self-education;

- formation of new competencies;

- realization of creative potential;

- increase personal self-esteem;

- development of personal qualities.

One possible approach to using the Internet for educational purposes is to use a structured approach that allows students to work on the Internet more productively, combining and combining a variety of information resources, using the abilities and skills of problem thinking. One of such technologies is the project technology of training with use of IT which in our research acts as a component of technical culture of applicants of education of a technical direction. Given the fact that a special place in the free economic zone is occupied by the research work of students, the integration of the method of projects using the Internet and roleplaying technical games deserves attention. This type of project is called Webquest.

Quest means an electronic or computer game, or a game with partial electronic tasks, in which the player must achieve a certain goal, using their own knowledge and experience, as well as communicating with the participants of the quest. Webquest in pedagogy is a problem task with elements of a role-playing game, for which the Internet information resources are used. Webquests are organized means of Web technologies in the WWW environment. Their organization is quite complex; they are aimed at developing students' skills of analytical and creative thinking; the teacher must have a high level of subject, methodological and informational 
and technical competence. Thus, Web Quest combines ideas of design method and game technology in the WWW environment by means of Web technologies.

Characteristic features of the Web Quest that distinguish it from other technologies, in particular from the project method, are the following:

First of all, the resources that contain the information needed to solve the

problem are determined in advance.

$>$ Second, the Web Quest clearly defines the procedure that a student mustfollow to obtain the desired result.

Third, a mandatory component of this technology is a list of the knowledge, skills and abilities that students can acquire after completing this Web Quest.

Fourth, the criteria for evaluating the completed tasks are clearly defined.

Evaluation of results for all tasks is carried out according to the following criteria: high level - 4 points; intermediate level -3 points; sufficient -2 points; low level - 1 point; 0 points - the task is performed inadequately, or not performed at all.

In order to determine the level of skills of higher education students to perform technical tasks by means of IT, we will analyze the data obtained during the tasks with applicants DI NU "OMA" (70 people), provide all the data, present them in the table (in tables $\mathrm{n}$ - number subjects, $\%$ - percentage of the total number).

Table1. The results of the survey conducted at the diagnostic stage of the experiment on the level of skills of higher education students to perform technical tasks by means of IT

\begin{tabular}{|l|l|l|}
\hline \multirow{2}{*}{\begin{tabular}{l} 
Levels of task performance \\
\cline { 2 - 3 }
\end{tabular}} & $\begin{array}{l}\text { The number of applicants at the appropriate level in each } \\
\text { task }\end{array}$ \\
\cline { 2 - 3 } & $\mathrm{n}$ & $\%$ \\
\hline High level & 10 & $14 \%$ \\
\hline Average & 35 & $50 \%$ \\
\hline Sufficient level & 15 & $22 \%$ \\
\hline Low level & 7 & $10 \%$ \\
\hline The task was performed inadequately & 3 & $4 \%$ \\
\hline
\end{tabular}

The results of the analysis of the first task of the Webquest "Technical Systems", in which it is necessary to answer questions of a technical nature. Ten applicants demonstrated a high level of knowledge. A huge part of the applicants coped with the tasks on their own. In the vast majority of applicants (35) the average level of action in accordance with the instructions. The actions of other applicants (10) correspond to a high level of action in accordance with the instructions for performing tasks that indicate significant success.

The results of the analysis for the second task "Creating a computer configuration". When analyzing the results of the second task of the diagnostic examination, aimed at clarifying the general composition and technical characteristics of the various components. [10] Some applicants begin to perform the task with a delay. Most of the applicants perform the task with prior understanding, impulsively, without changing the overall logical direction of the process of assembling the technical part of the task. The results of the analysis of the third task "Choose technical support that fully meets the needs of the applicant in a specific, technical field of activity." More applicants showed an average level. Most applicants (10) immediately began to perform tasks without focusing on the information material.

The results of the analysis on the fifth task "Content of technical culture of specialists in the maritime industry". The task was aimed at including in the work of graphs illustrating the dynamics of technical support of the specialist. Most of the applicants coped with the task quite well, the rest of the applicants coped with the task at the intermediate level without the help of a teacher. For clarity, we present the obtained data on all tasks in the form of a comparative histogram (Figure 1).

Thus, when conducting the experiment, we can say that a larger number of applicants for higher education DI NU "OMA", for all five tasks, showed the appropriate level of skills of higher education students to perform technical tasks by IT.

\section{CONCLUSION}

Thus, the study of technical courses on the basis of information technology contributes to the formation of technical culture as one of the integral parts of the general culture of the personality of the modern specialist, which aims to achieve high results in professional activities. It should be noted that a prerequisite for improving the level of skills of higher education students to perform technical tasks by means of IT is knowledge of IT, continuous creative self-education, development, improvement and more. 
The above areas and technologies will allow in the process of training higher education to develop the necessary for the individual in the formation of technical culture: critical thinking, reflection (self-analysis), autonomy, self-management and creativity of each person, which are essential in innovative models of technical culture. Further research, in our opinion, should be aimed at developing criteria for assessing the quality of education and skills acquisition, which will purposefully and thoroughly prepare graduates for work in modern conditions of higher education students' technical tasks by means of IT.

The task was performed inadequately

Low level

Sufficient level

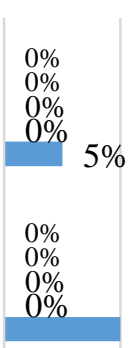

$10 \%$

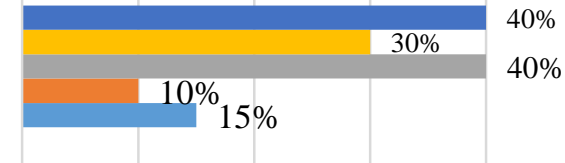

$40 \%$

(1)

Average level

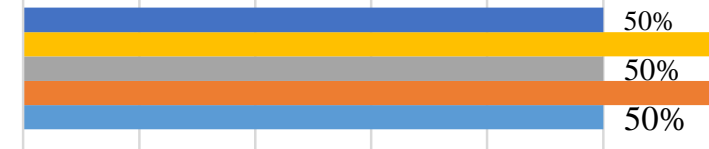

High level

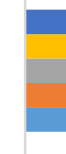

- task 5

$0 \%$

$10 \% \quad 20 \% \quad 30 \%$

$30 \%$

$40 \%$

$50 \%$

$60 \%$

$70 \%$

Figure 1 The data are obtained for all tasks

The purpose of our study is achieved, we can state that the teaching of technical disciplines using the latest technologies to train competitive in the global labor market applicants for higher education, which due to high quality training will meet the requirements of the world's leading shipping companies, especially in real education. conditions of rapid formation of science and technology, creation of science-intensive industries, integration into the world space, globalization, etc.

\section{REFERENCES}

[1] Gulara A. Mammadova, Firudin T. Aghayev and Lala A. Zeynalova (2019), "Use of Social Networks for Personalization of Electronic Education", International Journal of Education and Management Engineering, no. 2, pp. 25-33. DOI: 10.5815/ijeme.2019.02.03.

[2] Dr. Dawn Carmichael and Dr. Jacqueline Archibald (2019), "A Data Analysis of the Academic use of Social Media", International Journal Information Technology and Computer Science, no. 5, pp. 1-10. DOI: 10.5815/ijitcs.2019.05.01
[3] Malik Mubasher Hassan, Tabasum Mirza and Mirza Waseem Hussain (2020), “A Critical Review by Teachers on the Online Teaching-Learning during the COVID-19", International Journal of Education and Management Engineering, no. 5, pp. 17-27. DOI: 10.5815/ijeme.2020.05.03

[4] StanislavPiskunov, Maksym Iasechko, Nataliia Minko, Yurii Dolomakin, Oleksandr Palagin and Marina Musorina (2020), "Taking into account the Correlated Errors of Measurements when Estimating Parameters of Object Trajectory at Mechanical Movement", International Journal of Emerging Trends in Engineering Researc, vol. 8, no. 9, pp. 5603-5606. DOI: https://doi.org/10.30534/ijeter/2020/112892020

[5] Bakhmat Nataliia, Lyudmila Kotliar, Tetiana Zhytomyrska, Volodymyr Slabko, Viktoriia Zhurian, Oksana Pilevych and Iryna Smyrnova (2020), "Pedagogical Principles of Training Specialists in Public Administration and Management in the System of Vocational Education", Systematic Reviews in Pharmacy, vol. 
$11 \quad$ (10), $\quad$ pp. 203-207. DOI:10.31838/srp.2020.10.34

[6] Makarenko, L. Slabko, V. Kononenko, A. Musorina, M. and Smyrnova (2020), "Pedagogical aspects of ensuring the effsciency of education of applicants of higher education institutions of Ukraine in the process of research of technical discplines", Journal of Critical Reviews, vol. $7 \quad$ (13), pp. 116-118. DOI: $10.31838 /$ jcr.07.12.154

[7] Andriushchenko, K. Stefanyshyn, D. Sahaidak, M. Smyrnova, I. and Zhytomyrska, T. (2018), "Process of resources provision management of the enterprise's activity with consideration of gender factor", Eastern-European Journal of Enterprise Technologies, vol. 6(3-96), pp. 6-19. DOI: 10.15587/1729-4061.2018.150799
[8] Abimbola R. Iyanda, Olufemi D. Ninan and Damilola J. Odejimi (2018), "Students Conversation Management System", I.J. Education and Management Engineering, № 4, pp. 1-9. DOI: 10.5815/ijeme.2018.04.01.

[9] Kulish, A. Radul, V. Haleta, Y. Filonenko, O. and Karikh, I. (2020), "The Newest Digital Technologies in Education and the Prospects of Their Implementation in Ukraine", Propósitos y Representaciones, no. 8 (SPE2), pp. 684. DOI: http://dx.doi.org/10.20511/pyr2020.v8nSPE2.684

[10] Fomin, O. Lovska, A. Kudelya, V. and Smyrnova, I. (2020), "Determining the dynamic loading and strength of the bearing structure of a covered wagon when firing", Eastern-European Journal of Enterprise Technologies, vol. 4(7(106)), pp. 33-41. DOI: 10.15587/1729-4061.2020.208407 